
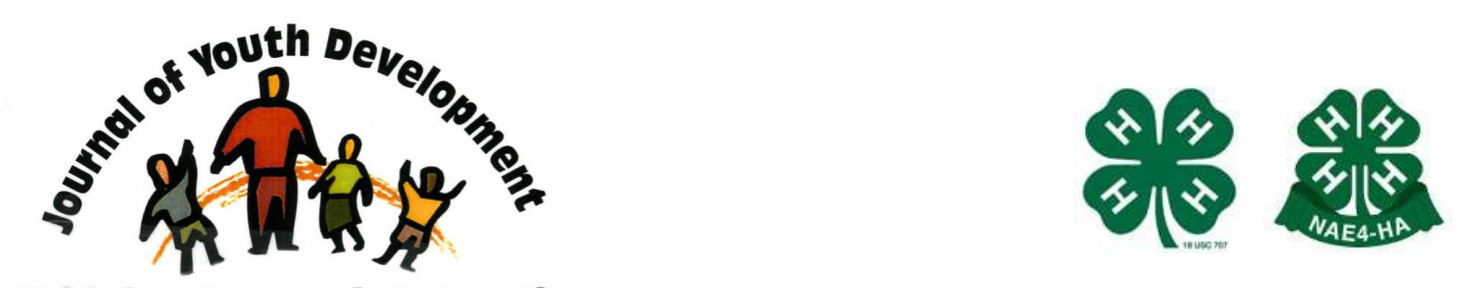

Bridging Research \& Practice

\title{
Weaving Evaluation into the Fabric of Youth Development
}

\author{
Ben Silliman \\ Department of 4-H Youth Development and Family \& Consumer Sciences \\ North Carolina State University \\ Raleigh, NC \\ Ben Silliman@ncsu.edu \\ Gene Shutt \\ Department of 4-H Youth Development and Family \& Consumer Sciences \\ North Carolina State University \\ Raleigh, NC \\ RShutt@etinternet.net
}

The authors acknowledge the assistance of Matthew Silliman and Isaac Davenport in data collection and preparation. This article is dedicated to Matthew Silliman (1990-2008). 


\title{
JOURNAL OF YOUTH DEVELOPMENT \\ bridging research and practice

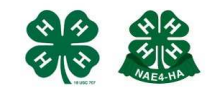

\section{Weaving Evaluation into the Fabric of Youth Development}

Ben Silliman and Gene Shutt North Carolina State University

\begin{abstract}
An Empowerment Evaluation process served to engage staff and campers and foster integration of authentic assessment methods into youth camp programming over a three-year period. Key elements to the process included program planning, staff training, timing and balance of action and reflection activities, data collection and management. Camp staff involved for 2-3 years reported improved focus and staff who served in the third year achieved mastery in communication, leadership, teaching, and management skills. A purposive sample of three different camp venues evaluated in Year 3 indicated that campers improved significantly in outdoor and life skills. Over $70 \%$ felt safe, supported, and enabled to build skills. Implications for practice, research, and policy are discussed.
\end{abstract}

\section{Introduction}

Youth programs such as summer camps are living systems that staff and campers know as few evaluators could hope to appreciate. Thus a professional evaluator is wise not to disrupt the flow of non-formal learning but rather collaborate with camp staff to assess processes and outcomes from the inside out. Such an integrated or embedded evaluation process adds value beyond generating accountability data. Engaging camp staff and campers in sharing experiences, achievements, and struggles enables both parties to build positive relationships, identify and adjust to changing needs, and use that knowledge and skill to optimize their camp experience. The purpose of this research report is to describe a program development process used to integrate evaluation into the fabric of a residential summer camp and describe outcomes for three diverse experiences served by that facility.

A growing body of research indicates that residential summer camps benefit youth campers (American Camp Association, 2005, 2006; Garst \& Bruce, 2003; Klem \& Nicholson, 2008; Loeser, Bailey, Benson, \& Dean, 2004) and teens or young adults who serve as counselors (Brandt \& Arnold, 2006; Garst \& Johnson, 2005; Garst \& Bruce, 2003). High quality camps provide supportive relationships (Spencer, Jordan, \& Sazama, 2004; Thurber, Scheuler, 
Scanlon, \& Henderson, 2007) in which youth can connect with nature, learn outdoor or specialized skills, and grow in social and leadership skills (American Camp Association, 2005, 2006). Most of these benefits derive from how programs are conducted; that is, their use of positive youth development practices (American Camp Association, 2005; Powell, 2003).

Camping programs face increasing pressure to demonstrate exemplary practices and outcomes, yet most must do so with limited expertise, budget, and time on evaluation tasks. Fortunately, timely investments in program development and staff training can set the stage for continuous quality improvement and sustained outcomes to meet these demands (American Camp Association, 2007; Henderson \& Bialeschki, 2007). Empowerment Evaluation (EE) (Fetterman \& Wandersman, 2005) provides a theoretical framework and skill set particularly well-adapted to program development and capacity-building in camp settings. In contrast to traditional approaches, EE operates as more of an internal evaluation process focused on selfdetermination and capacity-building. The evaluator acts less as an expert and more as coach and critical friend, collaborating with program staff toward mutually valued goals in program improvement and professional development. EE enables staff, who are well-positioned to judge children's needs and performance, to record data as it is generated, reflect with peers, supervisor, and project evaluator, and refine strategies to better meet needs of individual campers or groups. This approach seems consistent with recommendations for staff development by the American Camp Association (2007) and for engaging youth and staff in camp quality improvement (Bialeschki, n.d.). Alternative or authentic assessment (AA) methods recommended for school (Rennert-Ariev, 2005) and out-of-school (Fenichel \& Schweingruber, 2010) settings are compatible tools to implement Empowerment Evaluation and positive youth development practices.

\section{Evolution of the Camp Evaluation Process}

The evaluation process and outcomes described herein was woven into the fabric of camp life over a three year period. Within the broader framework of Empowerment Evaluation, annual orientation, cabin conversations, weekly staff debriefing, and end-of-season debriefing clarified the camp's mission (positive youth development through outdoor and life skills programming) and engaged staff and campers in annual and weekly "taking stock" and iterative planning activities.

In the first year, guided by positive youth development practices (Eccles \& Gootman, 2002) and program evaluation standards (Joint Committee, 1994), the authors developed a simple logic model and trained staff to complete checklists on outdoor skills and manage youth selfassessments of life skills (pre/post) and program climate (post). Camper feedback was overwhelmingly positive. However, counselor role overload, program time constraints, and camper literacy issues contributed to consistent stress over the evaluation process.

In the second year staff received more training and scheduled more time to observe and interact with campers on outdoor and life skills. Youth self-report was limited to post-camp assessment of program climate, using a PowerPoint program with infrared clickers. Debriefing conversations for campers and camp staff aided individual growth, group cohesion, and program adjustment. By the third year, experienced staff were able to blend observations, checklists, individual contacts, and debriefing conversations of cabin groups into the natural flow of programming. Most made use of suggested small group activities and conversation topics targeting life-skills to enhance this process. Campers were given a daily time to write in a 
journal and rest after lunch. Camper registration data was matched with process and outcome input, enabling group comparisons. A summary of youth and camp staff results follows.

\section{Methods}

A purposive sample was selected representing the facility's diverse camping groups, all of which served 10-15 year-olds. These included a traditional youth camp, 4-H Junior Camp (JR), including 51 boys and 49 girls $(n=108)$, a special audience camp, Operation Military Kids (OMK), reaching 41 boys and 37 girls $(n=79)$, and a wildlife/hunter safety theme camp, Fur, Fish, and Game (FFG) with 45 boys and 8 girls. All campers completed an enrollment form including demographic data. During each week, campers were assessed on two impact areas, outdoor skills and life skills, and one environmental factor, youth program climate. Outdoor skills in JR and OMK included archery and canoeing, assessed by instructional counselors using rubrics for safety and procedural skills. FFG campers completed a series of hunter safety and wildlife knowledge courses and assessments conducted by expert volunteers.

Each camper was assessed by his or her cabin counselor using a retrospective post-then-pre Life Skills Observation Checklist (LSOC) and journal. Six skills derived from the American Camp Association (ACA) study (2005): listening, conflict resolution, building friendships, new adventures, independence, and connecting to nature. Two skill sets were recommended by camp staff: practicing camp traditions (e.g., completing chores, etiquette, flag and other rituals) and exercising leadership. External observation was deemed more reliable than self-report as used in the ACA (2005) study since. Observations also reduced youth time on evaluation tasks and enhanced counselor awareness of camper growth. A pilot group of camp staff affirmed its face validity and utility in the month preceding camp. All counselors were trained on use of the tool before camp and checked periodically by the camp director throughout the summer.

Near the end of their weeklong camp experience, all participants completed a 30-item Youth Program Climate (YPC) survey using PowerPoint slides and infrared remote clickers. YPC construct validity rests on best practice program traits including safety, support, positive social norms, belongingness, skill-building, self-efficacy, and synergy with home and community (Eccles \& Gootman, 2002). Previous research found it reliable with child and teen audiences (Silliman, 2008, 2009). Campers also enjoyed a brief time each day to write in personal journals. These reflections were not collected for analysis but may have contributed in content or quality of nightly conversations in cabin groups.

Camp counselors (12 male, 14 female) self- assessed their own competencies before and after the camping season using the Camp Staff Skills assessment. Fifteen competencies representing communication, leadership, teaching, and management skills were drawn from camp job descriptions and prior research (Brandt \& Arnold, 2006; Garst \& Johnson, 2005). Fifteen additional items administered at the end of the season tapped staff perceptions of the Influence of Camp Staff Experience on factors ranging from desire to help others to career choice. Face and content validity for both scales were established through a panel of camp directors. Each scale enabled staff to reflect on core capacities and growth in the counseling experience. The camp director also completed individual observations on staff skill growth using the same scale. Camp Staff engaged in debriefing conversations together weekly, taking note of program strengths and needs for improvement. The camp director supervised all staff and was aided by several experienced counselors in coaching newer staff. Data for all scales was analyzed using SPSS-PC, Version 16. Informal notes from weekly staff debriefing conversations were examined for key themes to gain additional insights on the process. 


\section{Results}

\section{Youth Outcomes}

Results were tabulated for each camp in order to preserve the uniqueness of each audience and program yet facilitate comparison of trends across them. Outdoor Skills, Life Skills, and Youth Program Climate were assessed in each camp.

Outdoor Skills Observations. Campers in JR and OMK arrived at camp with scant awareness of safety rules or basic skills in archery or canoeing. At the conclusion of camp, over $90 \%$ of youth were able to describe and follow safety rules and complete the basic skills independently. FFG camper knowledge of wildlife and hunter safety was not assessed initially, but all those who participated earned the hunter safety certificate.

Life Skills Observation Checklist. Cabin counselors evaluated eight factors characteristic of the camping experience and provided retrospective ratings on each camper. Pre- and postcamp differences were significant for all variables in all camps. Trends for the greatest gains, by camp, were as follows:

- 4-H Junior Camp: Scale reliability for LSOC pre-test was (alpha $=.87$ ) and for the posttest (alpha $=.87)$. The five factors with greatest gains included Building Friendships (.72 on a 4-pt. scale), Listening (.67), Trying New Things (.59), Independence (.58), and Leadership (.52) were significantly higher than three areas with smallest gains, including Connecting to Nature (.44), Keeping Traditions (.44), and Resolving Conflicts (.39). Ratings of boys and girls for all areas showed no statistical differences on beginning, ending, or gain scores. Reliability for difference scores was high (alpha $=.84$ ).

- Operation Military Kids: Scale reliability for LSOC pre-test was (alpha $=.83$ ) and for the post-test (alpha $=.85$ ). The five factors with greatest gains include Leadership (.72), Building Friendships (.57), Conflict Resolution (.57), Keeping Traditions (.49), and Connecting to Nature (.48). Ratings of boys and girls for all areas showed no statistical differences on beginning, ending, or gain scores. Reliability for difference scores was high (alpha $=.84$ ). Results confirm earlier research indicating that expanding friendships and social skills, trying new activities, developing independence and leadership are among the most important results of attending Summer camp.

- Fur, Fish, and Game: Scale reliability for LSOC pre-test was (alpha $=.60$ ) and for the post-test (alpha $=.74)$. The five factors with greatest gains include Keeping Traditions (.64), Leadership (.63), Building Friendships, Conflict Resolution, and Independence (.50). Ratings of boys and girls for all areas showed no statistical differences on beginning, ending, or gain scores. Reliability for difference scores was high (alpha = .84). Results confirm earlier research indicating that expanding friendships and social skills, trying new activities, developing independence and leadership are among the most important results of attending summer camp.

Youth Program Climate Survey. Youth reported that their camp experiences were overwhelmingly positive. Alpha reliability for the scale in all three camps averaged .88. Over seventy percent in all camps agreed that they felt safe, supported, and enabled to build skills. Although as many as fifty-four percent (in OMK) disagreed that "Other Kids Cared," most (65$90 \%$ ) affirmed social norms for acceptance and belonging, teamwork (76-88\%), and service (84-91\%). Almost thirty-five percent in two camps indicated that "Conflicts Were a Problem," suggesting that individual hassles rather than overall camp culture were problematic. Further, 
around ninety percent youth in all camps did not report feeling "Embarrassed or Put Down." Although the vast majority (70-80\%) felt that adults listened and were approachable, nearly one quarter did not agree that adults were approachable.

In all camps, a large majority of youth (75\%) agreed that camp provided opportunities to set goals, learn new subjects, and gain skills. About the same percentage viewed camp as a place to take responsibility and make a difference. Over seventy percent of youth reported that the camp helped them grow in confidence, responsibility, and leadership. Over ninety percent felt that rules were clearly defined and seventy-five percent agreed that discipline was not too strict or loose. Over seventy-five percent agreed that activities promoted healthy habits.

Perspectives on program climate showed few differences by age, gender, or race, with significant differences only in the 4-H Junior Camp group. There, girls scored significantly higher than boys on viewing other kids as caring, discipline as appropriate, and seeing camp as a part of a broader social network. No differences were identified by race.

\section{Counselor Debriefing Observations}

Weekly debriefing conversations led by the camp director or his assistant enabled camp staff to reflect on programming and evaluation activities, to encourage and to learn from one another. Early in the Year 3 Evaluation staff rehearsed a shared understanding of Outdoor Skills Checklists and Life Skills Observations, then regularly checked procedures for implementing these tools. Discussions revealed the need for cabin counselors to assist instructional counselors in helping campers demonstrate Outdoor Skills Checklists. Staff noted that the Life Skills Observation rubric provided focus and clarity on carrying out the camp mission and building relationships with campers. They also shared ideas on how to frame questions with individuals or small groups that might result in more accurate and complete documentation of life skills growth. Staff generated several strategies for facilitating daily reflection on Nature, teamwork, or outdoor skills learning as well as ways to invite camper input on the next day's activities. During these times, staff also shared ideas to teach and discuss life skills such as conflict resolution and leadership. Debriefing also resulted in eliminating evaluation ideas such as efforts to monitor cabin routines (based on tedium and time constraints) or duplicate camper journals (limiting input demands, allowing greater privacy). Most importantly, debriefing facilitated mid-course program improvements and re-energizing around the mission which supported quality and continuity of programming (as evidenced by outcome and climate results) throughout the camping season.

\section{Counselor Outcomes}

Reliability for Camp Staff Skills assessments was high (alpha [pre] $=.85$, [post] $=.89$ ). At pretest, over fifty percent described themselves as having mastery in communication, leadership, teaching, and management skills. However, 11 of 15 items showed significant pre-post differences $(p<.05)$ : communicating with peers and with supervisors, leading small and large groups, mediating conflict resolution, dealing with difficult children, planning educational activities, decision-making, self-discipline, and problem solving. Non-significant differences in pre-post scores on listening, conflict resolution, teaching, teamwork, and handling emergencies were largely due to high levels of initial mastery.

In their weekly debriefing sessions with the camp director, staff identified critical strengths and weaknesses of their own and the larger camp schedule and took an active role in troubleshooting solutions. At the end of the season, responses to the Influence of Camp Experience survey (alpha $=.87$ ) indicated that staff viewed camp as a major influence on their 
growth in desire to help others (78\%), outdoor skills (71\%), practical skills (62\%), quality relationships (58\%), and safety practices (50\%). A high percentage of staff cited camp as a moderate or major influence on several other skills: creativity $(100 \%)$, appreciation of differences (96\%), workplace skills (96\%), empathy (88\%), self-efficacy $(88 \%)$, sense of citizenship (88\%), critical thinking (87\%), health habits and fitness (83\%).

\section{Discussion}

Using an Empowerment Evaluation approach over a three-year period, the authors and camp staff developed and implemented a plan integrating evaluation with educational and relational processes in a residential youth camp. The process seemed simple at first, and was in many ways an extension of the camp director's practice of taking stock, week-by-week through the camping season and annually between seasons. In fact, staff who began the process in 2006 could have answered in the affirmative to most of the items on the American Camp Association (ACA) Youth Outcomes Readiness Checklist (American Camp Association, 2007). Consistent with Checklist priorities, a mission statement and program goals were documented and interpreted to staff and parents and the camp was accredited with ACA. Also, stakeholders including campers, parents, and staff had been engaged in prior evaluation efforts, with results shared in program improvement and promotion. In addition, staff made efforts to assess camp culture and involve campers and staff. Finally, tools were developed and implemented to gather data.

Using the Empowerment Evaluation process, nearly two years of careful listening to counselor and camper feedback, refinements in camp procedures and evaluation instruments, and adjustments to training and mentoring were needed to turn apparent readiness into effective practice. By Year 3, staff became interpreters of the camp's mission, took stock of operations and opportunities, and adjusted plans to maximize their effectiveness with each camping group. Authentic assessment of outdoor skills enabled campers to learn and confirm skills interactively with experts. Debriefing and planning conversations in cabin and activity groups engaged youth in deciding, discovering, and discussing, which enabled staff to more accurately and effectively document growth in life skills.

The one-time, game-like Youth Program Climate survey provided a much more empowering and less stressful medium for evaluating camp experiences than the pencil-and-paper approach used in the first year. Ease-of-use and relatively few questions or difficulties in implementation, and high reliabilities confirmed the value of instruments and methods.

In the third year of the program development process youth outcomes were positive for all camping groups. Both boys and girls at all ages experienced significant growth in life skills such as building friendships, communicating, and working out conflicts. Most took advantage of unique opportunities to try new activities, develop independence, and practice leadership. Youth also grew closer to Nature and camp traditions emphasizing responsibility and teamwork. These results are consistent with research by the American Camping Association (2005) and others indicating that intensive camping experiences can have profound effects on the development of middle and high school youth. Practical and social competence, confidence and independence, positive connections with peers and adults, character in respecting rules and persons, and caring through collegiality and service are recognized as significant factors in successful transitions from middle childhood toward puberty and adolescence (Theokas, Almergi, Lerner, Dowling, Benson, Scales, \& vonEye, 2005). 
Each of the groups sampled found the camp climate safe, supportive, and skill-building. This feedback from youth supports the inference that life skills growth observed by camp staff resulted from the camp experience rather than observer bias. Gender differences in perceptions of social climate likely reflect patterns of affiliation (e.g., girls usually more collaborative, more socially skilled). Different views of belonging by age may reflect relative experience at camp or away from home, maturity, or circumstantial factors.

Camp counselors grew personally and professionally. Several staff were returning to counseling and all staff were hired for their skills in communication, leadership, teaching, and management. Nevertheless, almost all achieved higher levels of mastery in most skills and credited the camp counseling experience with moderate to major influence on their growth in these areas.

During weekly debriefing sessions, several counselors noted that life skills observations enabled them to see their activities in context of a larger goal and know what to look for and nurture with each camper in their charge, during both formal and informal contacts with campers. Thus for both campers and counselors the process of action and reflection reinforced practices of positive youth development

\section{Limitations}

This evaluation was, in fact, part of a multi-year process of refining program planning, implementation, and data collection. Samples are not representative of all campers but do reflect a diversity of audiences and programs in one camp. Although tools and methods were effective, they were not triangulated by external observers. Significant growth can occur in a brief time, yet camp programs are but a week in the lives of young people. Limited resources and contact information precluded follow-up contacts with campers or parents which may have reinforced or extended end-of-week reports. Staff training, coaching, and debriefing while fairly effective, was not extensive, and refinement of skills could significantly improve accuracy and utility of future evaluations.

\section{Recommendations}

The process of weaving evaluation into youth development programming in this residential camp accomplished much, yet much more remains to be accomplished. Suggested improvements for practice, research, and policy follow.

\section{Practice}

Program development is an iterative process that succeeds when program quality and outcome targets are identified accurately (e.g., consistent with youth development best practice and camp mission) and precisely (e.g., measurement is clear, detailed, and aligned with practice). Following the Empowerment Evaluation model, the process should engage a widening circle of stakeholders and gain much of its direction from them. Camp staff were central to this process. They served as front-line interpreters of camp priorities and activities to parents when they arrived at camp and to campers throughout the week. They designed and implemented program activities to teach content and life skills valued in the camp's mission. Simultaneously they observed campers and documented their progress. In addition, they facilitated feedback from campers on both needs and experiences. From these roles they provided practical insights for improving both program and evaluation processes. Given this history, refining resources, training, coaching, and support for camp staff is the top priority for continued improvement of programs and evaluations. 
Authentic assessments (e.g., Outdoor and Life Skills tools) and informal procedures (e.g., cabin conversation protocols) should be documented in greater detail. However, to avoid rigid application and facilitate creative use of tools, programs should invest heavily in training staff and engaging youth. Improvements in data collection such as automated registration and use of personal digital assistant devices (PDAs) would significantly improve just-in-time as well as long-term use of quantitative results. Cell phone cameras, Think pads, pre- or post-camp blogs could enhance gathering of qualitative data. Technology that reduces time and error in data recording and enables just-in-time results will greatly enhance staff efficiency and data utilization.

Addition of on-site external observers or multiple measures for key outcomes could enrich current results. For instance, youth self-assessments or feedback from parents or community youth leaders could add credence or clarification to authentic assessments.

However, perhaps the most important consideration for programming and evaluation is the balance of cost and benefit, especially since most camps last for only a week, aspire to relatively simple goals, and prioritize relationship and creativity. Based on the past three years' experience, extensive use of reflective or evaluative methods is best combined with documentation of a few critical indicators of value to specific stakeholders. In fact, a practical working knowledge of goal-setting, experimentation, and debriefing may be among the most worthwhile life skills that youth can learn experientially at camp or elsewhere.

\section{Research}

Insights and gaps identified by this study invite further investigation in a variety of youth programs and settings. Youth development professionals need to better understand the environments and interactive processes that facilitate growth and development in subject matter, self-awareness, and life skills. At the same time, researchers and practitioners need to better understand the types of outcomes that can be achieved in a brief program (e.g., one day to one week) and how those outcomes can be sustained. For instance, anecdotal comments from parents in prior years suggest that the camp experience may serve many purposes. Camps may be laboratories for learning skills not practiced elsewhere, such as water sports, environmental exploration, or hunter safety. In other cases, camp activities may be catalysts to learning or behavior changes such as using table manners or starting a horse club. For others, new friendships, self-awareness, or insights on life beyond one's hometown may set in motion patterns of maturation and relationship with lifelong effects. Some of these effects may be evident immediately while others may not be manifest to campers, staff, parents, or others until much later.

A more detailed examination is needed on the intersection between education and evaluation. The Empowerment Evaluation process and authentic assessment tools must be refined and tested under a variety of more rigorous conditions than was possible in this study. Another line of research might well examine how camp staff and campers make use of these processes in their subsequent learning and leadership. As technology tools become more affordable, researchers should examine their potential and limitations as youth development and as evaluation tools.

\section{Policy}

The processes and outcomes of this evaluation hold implications for youth programs, organizations, and funding agencies. Youth program directors and staff should develop logic 
models, lesson plans, and assessment tools with the help of evaluators long before the program season begins. Staff should be introduced to evaluation tools as methods to better understand and assist campers rather than as simply "reporting requirements" or "tests." At the organization level, investments in planning and training for program staff as well as support for data collection and reporting will likely yield higher quality programming as well as more reliable evaluation results. Professional organizations in youth development should place greater emphasis on empowerment evaluation methods since they are philosophically and practically consistent with youth development best practices.

Foundation and public funders should support development of processes that lead to quality climates. Like program staff, funders need to understand that developmental outcomes such as changes in self-awareness, self-discipline, and relationship skills may have more profound effects in the long-term than knowledge or skill gains. Funders must recognize the enormous potential of short-term programs to inspire, inform, or foster interaction, but also the limitations relative to year-round programs. Finally, as organizations and funders recognize the importance of integrating evaluation in education, they may be more likely to support investments in staff training and salaries and look beyond number-crunching as the only or best approach to demonstrating program benefits.

\section{References}

American Camp Association. (2007). Designing quality youth programs. Indianapolis:

American Camp Association. Retrieved online May 15, 2010 at www.acacamps.org/research/enhance/directions.php

American Camp Association. (2005a). Directions: Youth development outcomes of the camp experience. Retrieved online August 25, 2008 at www.acacamps.org/research/enhance/directions.php

American Camp Association. (2005b). Innovations: Developmental supports and opportunities of youths' experiences at camp. Retrieved online August 25, 2008 at www.acacamps.org/research/enhance/directions.php camp experience.

Bieleschki, D. (n.d.). Tips to help with your quality program improvement process. Retrieved online May 15, 2010 at www.acacamps.org/research/enhance/directions.php

Brandt, J., \& Arnold, M.E. (2006). Looking back, the impact of the 4-H camp counselor experience on youth development: A survey of counselor alumni. Journal of Extension, 44(6). Article Number 6RIB1.

Eccles, J., \& Gootman, J.A. (Eds., 2002). Community programs to promote youth development. Washington, DC: National Academy Press.

Fenichel, M., \& Schewingruber, H.A. (2010). Surrounded by science: Learning science in informal environments. Washington, DC: National Research Council.

Fetterman, D. M., \& Wandersman, A. (Eds.). (2005). Empowerment evaluation principles in practice. New York: Guilford Publications. 
Garst, B.A., \& Bruce, F.A. (2003). Identifying 4-H camping outcomes using a standardized evaluation process across multiple 4-H educational centers. Journal of Extension, 41(3). Retrieved on May 15, 2010 at www.joe.org/joe/2003june/rb2.shtml.

Garst, B., \& Johnson, J. (2005). Impacts of residential camp counseling on adolescent leadership skill development. Journal of Extension, 43(5). Article Number 5RIB5.

Henderson, K.A., Bialeschki, M.D. \& James, P.A. (2007). Overview of camp research. Child and Adolescent Psychiatric Clinics of North America 16, 755-767.

Henderson, K.A., Bialeschki, M.D., Thurber, C., Schueler, W.L., \& Marsh, P. (2007). Components of camp experiences for positive youth development. Journal of Youth Development, 3(1) http://wwwnae4ha.org/directory/jyd

Joint Committee on Standards for Educational Evaluation. (1994). Program evaluation standards. Second edition. Newbury Park, CA: Sage.

Klem, M.D., \& Nicholson, D.J. (2008). Proven effectiveness of Missouri 4-H camps in developing life skills in youth. Journal of Youth Development, 2(3). Article $0803 R S 003$.

Kress, C. (2004). Essential elements of 4-H youth development. Retrieved online at www.national4-hheadquarters.gov/library/elements.pdf

Loeser, D.M., Bailey, S.J., Benson, R.L., \& Dean, M.Y. (2004). Measuring impacts with young audiences: Adapting a life skills instrument for use with third- to fifth-grade youth. Journal of Extension, 42(4). Article Number 4RIB1.

Powell, G.M. (2003). Research notes: Youth development at summer camp. Camping Magazine, 76(3), 8-10.

Rennert-Ariev, P. (2005). A theoretical model for the authentic assessment of teaching. Practical Assessment, Research, and Evaluation. Practical Assessment, Evaluation, and Research, 10(2), $1-11$.

Silliman, B. (2009). NC 4-H Camps: A Snapshot, NC Extension Report. Raleigh, NC: North Carolina Cooperative Extension Service. Pub.No. 4-HEVAL-R002W, 2009.

Silliman, B. (2008). Taking Congress home: Effects of NC 4-H Congress on Youth behavior and interaction. Journal of Youth Development, $3(3)$. Article 0803PA001.

Theokas, C., Almergi, J.B., Lerner, R.M., Dowling, E.M., Benson, P.L., Scales, P.C., \& vonEye, A. (2005). Conceptualizing and modeling individual and ecological asset components of thriving in early adolescence. Journal of Early Adolescence, 25(1), 113-143.

Thurber, C.A., Scanlon, M.M., Scheuler, L., \& Henderson, K.A. (2007). Youth development outcomes of the camp experience: Evidence for multidimensional growth. Journal of Youth and Adolescence, 36, 241-254.

(C) Copyright of Journal of Youth Development Bridging Research and Practice. Content may not be copied or emailed to multiple sites or posted to a listserv without copyright holder's express written permission. However, users may print, download or email articles for individual use. 


\section{Appendix A: \\ NC 4-H Youth Program Climate Survey, Residential Camps}

Name;

Date:

Cabin:

For each item below, mark the word that fits your experience at this 4-H camp. Use the following scale: (A) Strongly Disagree; (B) Disagree; (C) Agree; (D) Strongly Agree. You have the option to skip any question or section if you choose. Your thoughtful answers will help improve this program.

STRONGLY

STRONGLY

DISAGREE DISAGREE AGREE AGREE

1. I felt safe from being hurt or injured.

A $\quad B$

C D

2. I was embarrassed or put down

A

3. Activities promoted healthy habits.

A

B

C

C

D

4. Adults listened to what I had to say.

A $\quad$ B $\quad$ C $\quad$ D

5. I felt comfortable going to adults for advice.....

6. Other kids cared about me.

A $\quad B$

A $\quad B$

C

C

7. Conflicts between people were a problem.

A

8. I learned to work with others as a team

A

9. Serving others and volunteering was important

A

10. I felt like I didn't belong.

A $\quad$ B $\quad$ C $\quad$ D

11. All kinds of kids were welcomed.

A $\quad B$

12. I learned to accept differences in others.

A

C

C

13. Activities taught me to develop a plan to reach my goals.

A $\quad$ B $\quad$ C

C

D

14. I was challenged to think and build skills.

15. There were opportunities to learn new subjects.

A

B

C

D

16. I felt that I could make a difference

A $\quad B$

C

A $B \quad$ C

17. I was encouraged to take responsibility.....

18. Perfect performance was more important than learning from mistakes.

A $\quad$ B $\quad$ C

19. Rules and expectations were clear.

20. Discipline was not too strict, not too loose......

21. Activities were just right for my age

A $\quad B$

A $\quad B$

B

C

A $\quad B$

C

C

A $\quad$ B $\quad$ C

22. I gained a broader view of $4-\mathrm{H}$.

A B

B $\quad$ C

beyond my community

C

A

B

C

D 


$\begin{array}{lll} & \text { STRONGLY } & \text { STRONGLY } \\ \text { This week... } & \text { DISAGREE DISAGREE AGREE AGREE }\end{array}$

25. I had fun at 4-H camp.

$\begin{array}{llll}\text { A } & \text { B } & \text { C } & \text { D } \\ \text { A } & \text { B } & \text { C } & \text { D } \\ \text { A } & \text { B } & \text { C } & \text { D } \\ \text { A } & \text { B } & \text { C } & \text { D } \\ \text { A } & \text { B } & \text { C } & \text { D } \\ \text { A } & \text { B } & \text { C } & \text { D }\end{array}$

26. I gained more confidence in myself..

27. I became more responsible for myself..

28. I learned to be a better leader...

29. I decided to do more in 4-H during the year...

30. Is an experience I would recommend to friends.

Thank you for participating in this survey and helping 4-H make the best better. 


\section{Appendix B: \\ NC 4-H Camp Staff Skills Survey}

Name:

Date:

\section{Camp Staff Skills \\ -End-of-Camp Self-Assessment-}

Rate yourself on the following skills related to camp work, using the following scale:

(A) Novice: Learning and beginning to practice roles and skills under guidance;

(B) Associate: Able to perform simple tasks on own or assist others in complex situations;

(C) Master: Able to handle most situations on own;

(D) Mentor: Able to train or coach others.

You have the option to skip any question or section if you choose. Your thoughtful answers will help improve this program.

NOVICE

1. Listening to youth with understanding............ A

2. Communicating clearly with peers.................. A

3. Communicating effectively with supervisors....

4. Leading small groups

ASSOCIATE MENTOR

5. Leading larger groups

A

A

6. Teaching or mediating conflict resolution........

7. Conflict resolution with peers.

$\begin{array}{llll}\text { A } & \text { B } & C & \text { D } \\ \text { A } & \text { B } & C & \text { D } \\ \text { A } & \text { B } & C & \text { D } \\ \text { A } & \text { B } & C & \text { D } \\ \text { A } & \text { B } & C & \text { D }\end{array}$

9. Teaching camp skills to children

10. Working effectively as a team member.

A

11. Planning an educational activity

B C

12. Handling emergency situations........................ A

13. Decision making to foster program effectiveness $A$

14. Self-discipline in completing responsibilities.... A $A$

15. Problem solving related to responsibilities.

$A$

B

B

B

B

$\begin{array}{ll}C & D \\ C & D \\ C & D \\ C & D \\ C & D\end{array}$




\section{Influence of Camp Staff Experience -End of Season Feedback-}

Indicate how your experience on camp staff influenced you in these areas, using the following scale: (A) No Influence; (B) Slight Influence; (C) Moderate Influence; (D) Major Influence.

INFLUENCE

None Slight Moderate Major

16. Critical thinking

$\begin{array}{llll}\text { A } & \text { B } & \text { C } & \text { D } \\ \text { A } & \text { B } & \text { C } & \text { D } \\ \text { A } & \text { B } & \text { C } & \text { D } \\ \text { A } & \text { B } & \text { C } & \text { D } \\ \text { A } & \text { B } & \text { C } & \text { D } \\ \text { A } & \text { B } & \text { C } & \text { D } \\ \text { A } & \text { B } & \text { C } & \text { D } \\ \text { A } & \text { B } & \text { C } & \text { D } \\ \text { A } & \text { B } & \text { C } & \text { D } \\ \text { A } & \text { B } & \text { C } & \text { D } \\ \text { A } & \text { B } & \text { C } & \text { D } \\ \text { A } & \text { B } & \text { C } & \text { D }\end{array}$

17. Learning to lear

18. Creativity

19. Empathy.

20. Appreciation of differences...

21. Desire to help others.

22. Practical skills (working with my hands)

23. Outdoor skills (water, target sports, camping)....

24. Workplace skills (organization, efficiency, etc.)...

25. Health habits and fitness...........................

26. Self-efficacy.....

27. Safety practices and first aid

$\begin{array}{llll}\text { A } & \text { B } & \text { C } & \text { D } \\ \text { A } & \text { B } & \text { C } & \text { D } \\ \text { A } & \text { B } & \text { C } & \text { D }\end{array}$

Thank you for participating in this survey and helping 4-H make the best better. 